\title{
Simultaneous Saccharification and Fermentation of Ground Corn Stover for the Production of Fuel Ethanol Using Phanerochaete chrysosporium, Gloeophyllum trabeum, Saccharomyces cerevisiae, and Escherichia coli K011
}

\author{
Vincent, Micky ${ }^{1,2,3}$, Anthony L. Pometto III ${ }^{4}$, and J. (Hans) van Leeuwen ${ }^{2,3,5,6 *}$ \\ ${ }^{1}$ Department of Molecular Biology, Faculty of Resource Science and Technology, Universiti Malaysia Sarawak, 94300 Kota Samarahan, \\ Sarawak, Malaysia \\ ${ }^{2}$ Department of Civil, Construction, and Environmental Engineering, Iowa State University, Ames, IA 50011, USA \\ ${ }^{3}$ Biorenewable Resources and Technology Program, Iowa State University, Ames, IA 50011, USA \\ ${ }^{4}$ Department of Food Science and Human Nutrition, Clemson University, Clemson, SC 29634, USA \\ ${ }^{5}$ Department of Agricultural and Biosystems Engineering, Iowa State University, Ames, IA 50011, USA \\ ${ }^{6}$ Department of Food Science and Human Nutrition, Iowa State University, Ames, IA 50011, USA
}

Received: October 21, 2010 / Revised: April 11, 2011 / Accepted: May 7, 2011

\begin{abstract}
Enzymatic saccharification of corn stover using Phanerochaete chrysosporium and Gloeophyllum trabeum and subsequent fermentation of the saccharification products to ethanol by Saccharomyces cerevisiae and Escherichia coli K011 were achieved. Prior to simultaneous saccharification and fermentation (SSF) for ethanol production, solid-state fermentation was performed for four days on ground corn stover using either $P$. chrysosporium or $G$ trabeum to induce in situ cellulase production. During SSF with $S$. cerevisiae or $E$. coli, ethanol production was the highest on day 4 for all samples. For corn stover treated with $P$. chrysosporium, the conversion to ethanol was $2.29 \mathrm{~g} / 100 \mathrm{~g}$ corn stover with $\boldsymbol{S}$. cerevisiae as the fermenting organism, whereas for the sample inoculated with $E$. coli K011, the ethanol production was $4.14 \mathrm{~g} / 100 \mathrm{~g}$ corn stover. Corn stover treated with $G$ trabeum showed a conversion 1.90 and $4.79 \mathrm{~g} / 100 \mathrm{~g}$ corn stover with $S$. cerevisiae and $E$. coli K011 as the fermenting organisms, respectively. Other fermentation co-products, such as acetic acid and lactic acid, were also monitored. Acetic acid production ranged between 0.45 and $0.78 \mathrm{~g} / 100 \mathrm{~g}$ corn stover, while no lactic acid production was detected throughout the 5 days of SSF. The results of our experiment suggest that it is possible to perform SSF of corn stover using $P$. chrysosporium, $G$ trabeum, $S$. cerevisiae and $E$. coli K011 for the production of fuel ethanol.
\end{abstract}

Keywords: Phanerochaete chrysosporium, Gloeophyllum trabeum, Saccharomyces cerevisiae, Escherichia coli K011, solid subtrate fermentation, simultaneous saccharification and fermentation (SSF)

\footnotetext{
* Corresponding author

Phone: +515 294-5251; Fax: +515 294-8216;

E-mail: leeuwen@iastate.edu
}

The ethanol presently used for transportation purposes is conventionally produced in large quantities from corn grain and sugarcane juice. However, this practice is only a temporary solution as it conflicts with the food and feed industry [7]. Thus, there is great interest in the development of fuel ethanol from agricultural residues and other lignocellulosic feedstocks, which are inexpensive and are the most abundant bioresources available in the biosphere [11]. Currently, corn stover biomass is considered to be one of the primary lignocellulosic candidates for use in cellulosic bioethanol production because it is an abundant agricultural by-product in many European countries and in the USA, and it can be collected during harvest $[46,51]$. Although promising, the use of corn stover as a raw material to produce ethanol presents many challenges; unlike starch from corn, the polysaccharides in stovers are cellulose and hemicellulose, which are difficult to degrade [20, 24, 33]. Thus, hydrolyzing these components into fermentable sugars is essential to the efficient and economical production of cellulosic ethanol [5].

Biohydrolysis of cellulose and hemicellulose is an enzymatic process carried out by a family of cellulolytic and hemicellulolytic enzymes that are highly specific [24]. These enzyme consortia are usually a mixture of several enzymes that may include endoglucanases, exoglucanases or cellobiohydrolases, glucosidases or cellobiases, endoxylanases, xylosidases and galactosidases, among others [1,31, 50, 54]. The conventional method for the breakdown of lignocellulosics to fermentable sugars requires the use of expensive commercial enzymes [12, 26, 53]. However, these enzymes are not only substrate specific, they are largely susceptible to inhibition from compounds usually associated with lignin. Thus, prior to enzymatic hydrolysis, pretreatment of ground lignocelluloses is required [21]. 
Pretreatment of plant biomass is crucial for the production of cellulosic ethanol as it greatly improves the enzymatic accessibility of the feedstock [13, 19, 25, 41, 42]. In recent years, several pretreatment methods have been tested on corn stover that involve physical, chemical, or physicochemical procedures or a combination thereof $[16,47,56]$. However, these technologies are energy intensive, environmentally unfriendly, and may produce many toxic by-products such as weak acids, phenolic derivatives, and furans that inhibit alcoholic fermentation $[6,7,21]$. Therefore, it is imperative to develop alternative means of lignocellulosic saccharification that can overcome these obstacles.

One potential form of pretreatment and hydrolysis of lignocellulosic materials relies on biological means $[15$, 49]. This type of procedure usually involves lignocellulolytic fungal species such as Phanerochaete chrysosporium and Gloeophyllum trabeum [38, 40, 43-45]. P. chrysosporium is a white-rot fungus that has been studied extensively in the degradation of plant cell wall components including cellulose, hemicellulose, and lignin [23, 54]. P. chrysosporium performs lignocellulolytic processes using the various ligninolytic peroxidases, cellulases, and hemicellulases it is known to secrete $[30,50,54]$. G. trabeum is a brown-rot basidiomycete. Like a typical brown rot-fungus, G. trabeum primarily attacks the polysaccharide while leaving the brown pigmented lignin behind [8]. These degradative processes culminate in the rapid loss of wood strength and darkening of the affected substrate [10]. G. trabeum is known to secrete a family of potent cellulolytic enzymes consisting of endoglucanases, exoglucanases, beta-glucosidases, and other hemicellulases $[8,22]$. In contrast to white-rot fungi, $G$. trabeum rapidly degrades cellulose and hemicellulose while leaving the undigested lignin to be modified mainly through demethoxylation and demethylation mechanisms [4].

In this paper, we report the use of in situ cellulases and hemicellulases from $P$. chrysosporium and G. trabeum for the saccharification of corn stover cellulose that is subsequently fermented to ethanol by Saccharomyces cerevisiae and Escherichia coli K011. We performed our work under conditions and with equipment that would generate commercially relevant results.

\section{Materials AND MethodS}

\section{Corn Stover Analysis}

Corn stover was obtained from the Department of Agronomy, Iowa State University, USA. Field-dried corn leaf and corn stalk were ground in a Wiley mill to pass through a $2 \mathrm{~mm}$ screen, and then screened using a 20 mesh sieve and further dried in an oven at $80^{\circ} \mathrm{C}$ for 4 days prior to compositional analysis. The composition of cellulose and hemicellulose was determined by the Department of Agronomy, Iowa State University, using the ANKOM method (ANKOM Technology Corp., Fairport, NY, USA) as previously described [52]. The Klason lignin content was determined using a modified Klason lignin assay following the method of Crawford and Pometto [9] with slight modification, whereby glass fiber filters $(1.6 \mu \mathrm{m})$ (Fisherbrand, Fisher Scientific, Pittsburgh, PA, USA) were used instead of Whatman No.1 filter papers for capturing lignin residues. This assay measures lignin as the acid-insoluble fraction of lignocellulosic material after hydrolysis by strong acid $\left(\mathrm{H}_{2} \mathrm{SO}_{4}\right)$ and heat. The residue on the filter paper was thoroughly rinsed with deionized water and dried in an oven at $105^{\circ} \mathrm{C}$ for 4 days. The Klason lignin content was determined as the weight of dry residue collected on the filter paper.

\section{Microorganisms}

All of the cultures used in this study were obtained from the American Type Culture Collection (ATCC; Rockville, MD, USA) and included P. chrysosporium (ATCC 24725), G. trabeum (ATCC 11539), S. cerevisiae (ATCC 24859), and E. coli K011 (ATCC 55124). Fungal cultures were revived by inoculating them into potato dextrose broth (PDB) (Difco, Becton Dickinson and Co., Sparks, MD, USA) and the bacterial culture by inoculating into LB broth (Becton Dickinson), followed by incubation with shaking at $24^{\circ} \mathrm{C}[43,44]$. Stock cultures were stored in yeast malt extract (YM) broth (Becton Dickinson) supplemented with $20 \%(\mathrm{v} / \mathrm{v})$ glycerol at $-80^{\circ} \mathrm{C}$ in an ultralow temperature freezer (So-Low Environmental Equipment Co., Inc., Cincinnati, OH, USA) for long-term storage.

\section{P. chrysosporium and G. trabeum Culture Preparation}

$P$. chrysosporium and G. trabeum seed cultures were prepared from spores in 11 of YM broth and incubated at $30^{\circ} \mathrm{C}$ with agitation at $150 \mathrm{rpm}$. After 7 days of growth, fungal mycelia (approximately 2$3 \mathrm{~mm}$ in diameter) were harvested via centrifugation in a sterilized 11 polypropylene centrifuge bottle (Nalgene, Nalge Nunc, Rochester, NY, USA), at $7,277 \times g$ for $20 \mathrm{~min}$ using a Sorvall-RC3B Plus centrifuge (Thermo Fisher Scientific, Wilmington, DE, USA) [38]. The fungal pellets were rinsed with fungal mineral salt solution $(\mathrm{pH}$ 4.5-4.8; $50 \mathrm{mM}$ phosphate buffer $+0.5 \%\left(\mathrm{NH}_{4}\right)_{2} \mathrm{SO}_{4}+$ basal medium). Basal medium was prepared according to the formulation of Shrestha et al. [44], consisting of $0.25 \mathrm{~g}$ of $\mathrm{KH}_{2} \mathrm{PO}_{4}$ (Fisher Scientific, Pittsburgh, PA, USA), $0.063 \mathrm{~g}$ of $\mathrm{MgSO}_{4} \cdot 7 \mathrm{H}_{2} \mathrm{O}$ (Fisher Scientific), $0.013 \mathrm{~g}$ of $\mathrm{CaCl}_{2} \cdot 2 \mathrm{H}_{2} \mathrm{O}$ (Fisher Scientific), and $1.25 \mathrm{ml}$ of trace element solutions in 11 of deionized water [43].

\section{Solid Substrate Fermentation for Enzyme Induction}

All ground corn stover used in this study received no pretreatment except any weathering that might have occurred in the field prior to harvest. Prior to the addition of fungal inoculum for enzyme induction, $2 \mathrm{~g}$ of ground stover and glass marbles with $5 \mathrm{ml}$ of fungal mineral salt solution were sterilized in $250 \mathrm{ml}$ polypropylene bottles (Nalgene) at $121^{\circ} \mathrm{C}$ for $1 \mathrm{~h}$ followed by rapid exhaust. Two $\mathrm{ml}$ of fungal biomass $[1.5 \%(\mathrm{w} / \mathrm{v})$ P. chrysosporium and $1.0 \%(\mathrm{w} / \mathrm{v}) G$. trabeum] in mineral salt solution was then added. The bottles were rolled on their sides and the marbles assisted in uniformly dispersing and coating the corn stover and fungi mixture along the inner surface $[38,44]$. Solid substrate fermentation was then performed for 4 days at $37^{\circ} \mathrm{C}$ in a humidified incubator for in situ production of cellulases and hemicellulases prior to the addition of the ethanolic microorganism.

\section{Protein Assay}

Total protein was analyzed using a NanoDrop 1000 Spectrophotometer (Thermo Fisher Scientific). The NanoDrop 1000 module measures 
protein absorbance at $280 \mathrm{~nm}$ (A280) and calculates the concentration $(\mathrm{mg} / \mathrm{ml})$ from a $2 \mu \mathrm{l}$ sample. Sample aliquots of $1.5 \mathrm{ml}$ were taken from stover treated with fungal cultures and washed with minimal salt medium on day 4. The supernatant was centrifuged using a MiniSpin Plus centrifuge (Eppendorf, Hauppauge, NY, USA) at $1,118 \times g$ for $5 \mathrm{~min}$ and filtered through a $0.2 \mu \mathrm{m}$ nylon syringe filter (VWR International, Batavia, IL, USA). Portions of the filtered solution were also used to perform the enzyme activity assay.

\section{Enzyme Activity Assay}

A specific enzyme activity assay was performed using the protocol described by the official National Renewable Energy Laboratory (NREL) procedure [2]. This method is based on the International Union of Pure and Applied Chemistry (IUPAC) guidelines to determine cellulase activity in terms of "filter-paper units" (FPU) per milliliter (FPU/mL) of an original enzyme preparation [18].

\section{S. cerevisiae and E. coli K011 Culture Preparation}

Culture inocula of S. cerevisiae and E. coli $\mathrm{K} 011$ were prepared by growing cultures in $50 \mathrm{ml}$ of sterile $\mathrm{YM}$ broth at $32^{\circ} \mathrm{C}$ with constant agitation at $120 \mathrm{rpm}$. Cells were harvested via centrifugation in $50 \mathrm{ml}$ conical centrifuge tubes (BD Falcon, BD, Franklin Lakes, NJ, USA) at 2,852 $\times g$ for $10 \mathrm{~min}$ in a Beckman J2-21 centrifuge (Beckman Coulter, Inc., Brea, CA, USA). Prior to use in SSF, cell counts were set at $10^{7}-10^{8} \mathrm{CFU} / \mathrm{ml}$ as determined turbidometrically at $600 \mathrm{~nm}$ via a standard curve [33].

\section{Simultaneous Saccharification and Fermentation (SSF)}

SSF reactions were carried out in $250 \mathrm{ml}$ polypropylene bottles with batch cultures of $100 \mathrm{ml}$ final volume, consisting of $25 \mathrm{ml}$ of $4 \times$ yeast extract broth $\left[1.8 \mathrm{~g}\right.$ of yeast extract (Difco), $0.07 \mathrm{~g}$ of $\mathrm{CaCl}_{2} \cdot 2 \mathrm{H}_{2} \mathrm{O}$ (Fisher Scientific), $0.45 \mathrm{~g}$ of $\mathrm{KH}_{2} \mathrm{PO}_{4}$ (Fisher Scientific), $1.2 \mathrm{~g}$ of $\left(\mathrm{NH}_{4}\right)_{2} \mathrm{SO}_{4}$ (Fisher Scientific), and $0.3 \mathrm{~g}$ of $\mathrm{MgSO}_{4} \cdot 7 \mathrm{H}_{2} \mathrm{O}$ per liter (Fisher Scientific)] [44] and $66 \mathrm{ml}$ of basal medium (pH 4.5-4.8; $50 \mathrm{mM}$ phosphate buffer $+0.5 \%\left(\mathrm{NH}_{4}\right)_{2} \mathrm{SO}_{4}+$ basal medium). The bottles were then aseptically inoculated with $10^{7}-10^{8} \mathrm{CFU} / \mathrm{ml} S$. cerevisiae and E. coli $\mathrm{K} 011$ suspensions. Batch culture fermentations were incubated at $37^{\circ} \mathrm{C}$ under static conditions. These samples were then subjected to SSF under anaerobic conditions for 5 days. The SSF experiments were performed in triplicate $(n=3)$.

\section{High-Performance Liquid Chromatography (HPLC) Analyses}

Sample aliquots of $1.8 \mathrm{ml}$ were taken daily, centrifuged at $1,118 \times \mathrm{g}$ for $5 \mathrm{~min}$, and filtered through a $0.2 \mu \mathrm{m}$ nylon syringe filter. Glucose, xylose, and the fermentation products (ethanol, acetic acid, and lactic acid) were analyzed using a Waters High Performance Liquid Chromatograph (Millipore Corp., Milford, MA, USA) equipped with a Waters Model 401 refractive index detector, column heater, autosampler, and computer controller. The separation and analysis of ethanol and other fermentation constituents were done on a Bio-Rad Aminex HPX-8711 column $(300.0 \times 7.8 \mathrm{~mm}$; Bio-Rad Chemical Division, Richmond, CA, USA) using $0.012 \mathrm{~N} \mathrm{H}_{2} \mathrm{SO}_{4}$ as the mobile phase at a flow rate of $0.6 \mathrm{ml} / \mathrm{min}$, a $20 \mu \mathrm{l}$ injection volume, and a column temperature of $65^{\circ} \mathrm{C}[28,37]$.

\section{Total and Reducing Sugar Assays}

Filtered supernatants from the fermentation broth were tested for free reducing sugar and total reducing sugars via the Somogyi-Nelson [3] and phenol-sulfuric [9] methods, respectively. The Somogyi-
Nelson carbohydrate assay was performed at $500 \mathrm{~nm}$ with a glucose standard, whereas total sugars were determined via the phenol-sulfuric carbohydrate test at $490 \mathrm{~nm}$ with a glucose standard. Absorbance was read on a SpectraMax Plus384 spectrophotometer (Molecular Devices, Inc., Sunnyvale, CA, USA). The absorbance readings were then converted into equivalent sugar concentrations $(\mathrm{g} / \mathrm{l})$ based on a standard glucose solution curve. All sugar analyses were performed in triplicate $(n=3)$.

\section{Statistical Analyses}

SSF results were statistically analyzed using JMP 8.0 statistical software (SAS Institute, Inc., Cary, NC, USA). The data on ethanol production were fitted to exponential fit models, and a significant difference of $p$ value of 0.05 was employed. Student's t test analyses were also performed on all final data sets to determine multiple comparisons of ethanol production. A p-value of less than 0.05 was considered significantly different.

\section{RESUlts AND DisCuSSION}

\section{Enzyme Induction on Untreated Corn Stover}

In this study, we performed SSF on ground corn stover without pretreatment. The main components of the corn stover were hemicellulose, cellulose, lignin, and ash (Table 1). Interestingly, the compositional analysis revealed a high ash content. This observation is in agreement with that of a previous analysis $[36,48]$ in which the ash content of corn leaf and corn stalk were found to be considerably higher than that of other biomass. A flow chart of our experimental design is shown in Fig. 1. Unlike the SSF process in previous works, ours does not use pretreated corn stover samples $[13,19,25,42]$ or the addition of expensive commercial enzymes $[12,26,53]$. Instead, cellulases and hemicellulases are produced by $G$ trabeum and $P$. chrysosporium in situ upon corn stover enzyme induction performed via solid substrate fermentation in a $\mathrm{pH}$ range of $4.5-4.8$ at $37^{\circ} \mathrm{C}$ for 4 days, conditions that are suitable not only for the growth of the fungi but also for production of cellulolytic enzymes $[38,43,44]$. As seen in Table 2, our assay using the NanoDrop 1000 spectrophotometer indicated that protein was produced during the induction stage, and production was higher in the stover and $P$. chrysosporium combination compared with the stover and $G$. trabeum combination, at 14.06 and $11.61 \mathrm{mg} / \mathrm{ml}$, respectively.

Table 1. Composition of corn stover (as percentage based on dry weight; $n=3$ ).

\begin{tabular}{lc}
\hline Main component & $\begin{array}{c}\text { Composition based on cell mass } \\
(\%, \mathrm{w} / \mathrm{w})\end{array}$ \\
\hline Cellulose & 38.08 \\
Hemicellulose & 30.72 \\
Klason lignin & 20.70 \\
Ash & 8.77 \\
Others & 0.31 \\
\hline
\end{tabular}




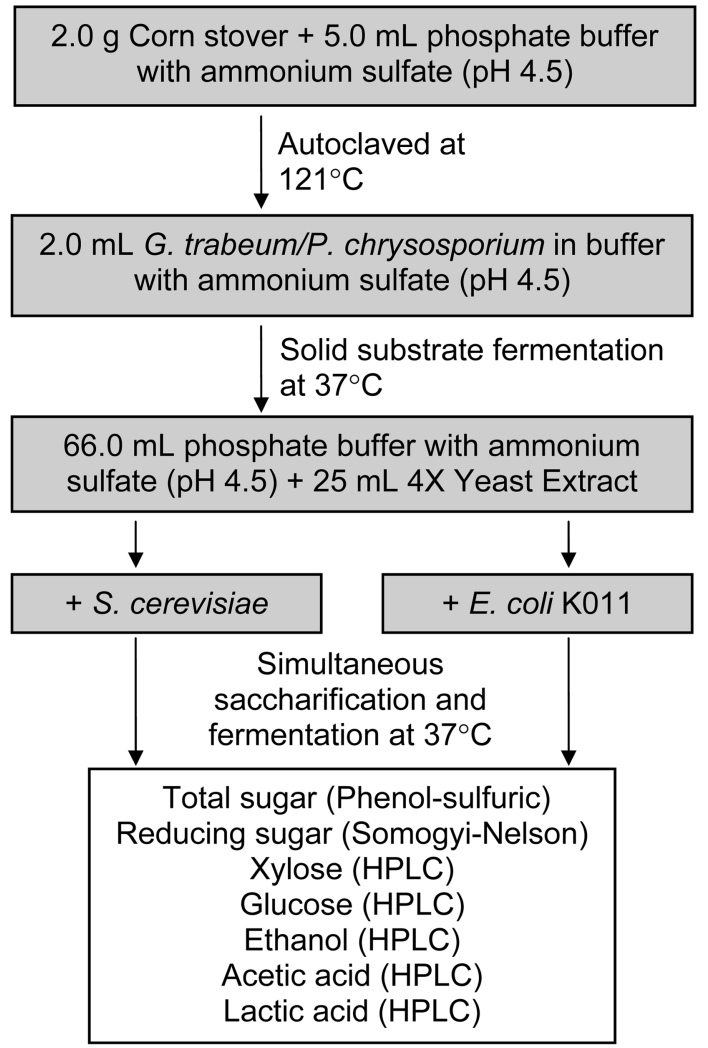

Fig. 1. Flow chart outlining the steps of solid substrate fermentation by $G$. trabeum and $P$. chrysosporium of corn stover without pretreatment, followed by SSF using $S$. cerevisiae and $E$. coli K011.

Next, quantitative enzyme activity was determined according to the IUPAC protocol [18], which interprets the filter paper unit activity (FPase) based on a value of $2.0 \mathrm{mg}$ of reducing sugar as glucose from $50 \mathrm{mg}$ of filter paper, at $4 \%$ conversion, in $1 \mathrm{~h}$ (units FPU/ml) [2]. Enzyme assays to determine the FPase showed that more cellulase was being secreted by the brown-rot fungus, at $1.72 \mathrm{FPU} / \mathrm{ml}$, compared with the white-rot fungus, at $0.65 \mathrm{FPU} / \mathrm{ml}$. This concentration, however, is not correlated with the amount of total protein being produced extracellularly, as mentioned earlier. According to the literature, the white-rot fungus $P$. chrysosporium produces additional extracellular enzymes including laccases and peroxidases when grown in ligninimpregnated biomass such as corn stover and other lignocellulosic material [50,54].

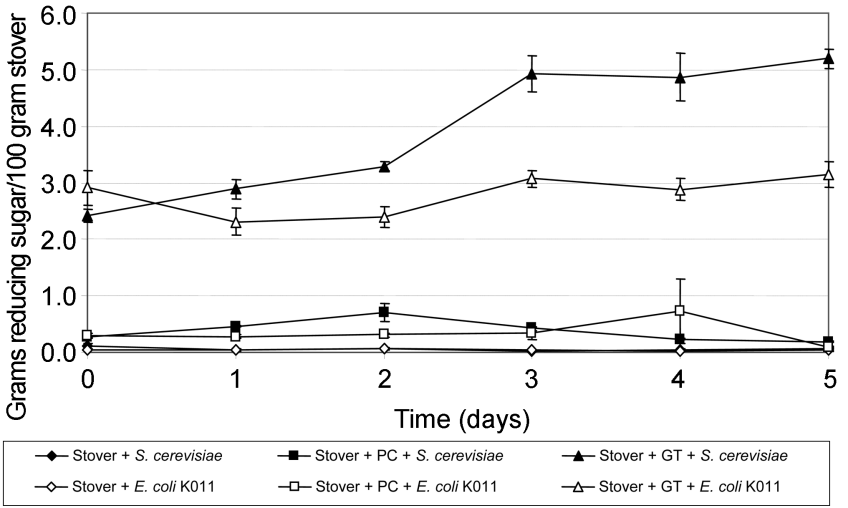

Fig. 2. Time course of reducing sugar production, as determined by the Somogyi-Nelson method.

Data points represent the average of three independent experiments $(n=3)$. PC, P. chrysosporium; GT, G. trabeum. Time zero is after 4 days of solid substrate fermentation with a specific fungus ( $P$. chrysosporium or $G$. trabeum).

\section{In Situ Enzymatic Hydrolysis}

The efficiency of cellulolytic enzyme hydrolysis of lignocelluloses was evaluated and validated via assays for saccharification and fermentation products. Saccharification of the stover to its free reducing and total sugars was measured using the Somogyi-Nelson and phenol-sulfuric methods. After the 4-day enzyme induction period (day 0 of $\mathrm{SSF}$ ), between 2.42 and $2.91 \mathrm{~g}$ of reducing sugar per $100 \mathrm{~g}$ of stover was detected in the broth of the G. trabeumtreated stover and $0.23-0.29 \mathrm{~g}$ in the broth of the $P$. chrysosporium-treated stover. Although there was a significant difference in the amount of reducing sugar, the result was quite different for total sugars. The total sugar profile was similar for the two treatments on day 0 of SSF and ranged from 5.57 to $5.94 \mathrm{~g}$ of sugar per $100 \mathrm{~g}$ of stover. Both of these assays support the ability of both fungal strains to perform in situ saccharification, and these trends were observed throughout the 5-day SSF period (Fig. 2 and 3), especially for total sugars.

To supplement the carbohydrate assay, the presence of glucose and xylose were also investigated using HPLC, as these sugars are the main monomeric end products from cellulosic and hemicellusic polymers [20,27]. During the anaerobic fermentation period, no glucose was detected; this result is a good indication that efficient conversion to ethanol was achieved. Xylose was detected in all fungitreated samples that were inoculated with $S$. cerevisae, as

Table 2. Enzyme activity and total protein $(n=3)$.

\begin{tabular}{lcr}
\hline & Corn stover + P. chrysosporium & Corn stover + G. trabeum \\
\hline Enzyme assay $(\mathrm{FPU} / \mathrm{ml})^{\mathrm{a}}$ & 0.65 & 1.72 \\
Protein assay $(\mathrm{mg} / \mathrm{ml})^{\mathrm{b}}$ & 14.06 & 11.61 \\
\hline
\end{tabular}

\footnotetext{
${ }^{a}$ Filter paper unit activities (FPase) based on a value of $2.0 \mathrm{mg}$ of reducing sugar as glucose from $50 \mathrm{mg}$ of filter paper, at $4 \%$ conversion, in $1 \mathrm{~h}$ (units FPU/ml).
}

${ }^{\mathrm{b}}$ Protein was determined using a NanoDrop 1000 Spectrophotometer. 


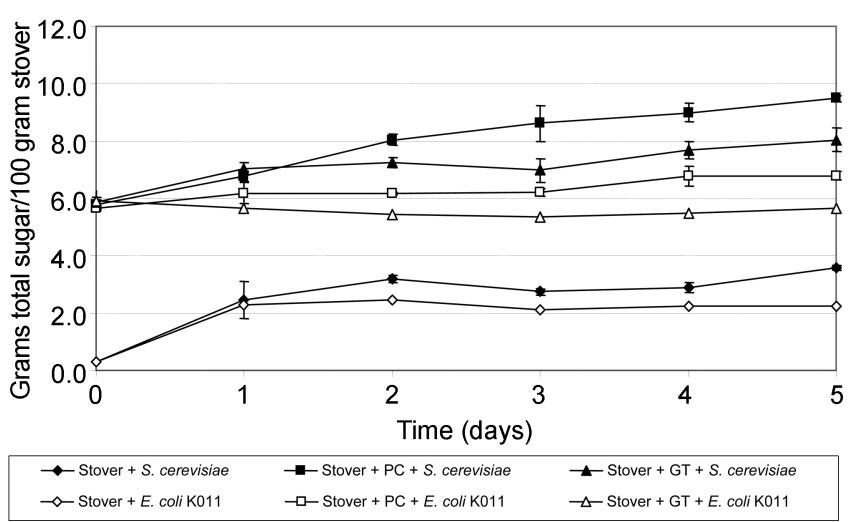

Fig. 3. Time course of total sugar production, as determined by the phenol-sulfuric method.

Data points represent the average of three independent experiments $(n=3)$. PC, P. chrysosporium; GT, G. trabeum. Time zero is after 4 days of solid substrate fermentation with a specific fungus (P. chrysosporium or $G$. trabeum).

shown in Fig. 4. This observation was expected since $S$. cerevisae cannot utilize pentoses such as xylose [14, 29].

\section{Simultaneous Saccharification and Fermentation of Corn Stover}

The fermentability of the saccharification products was evaluated using $S$. cerevisiae and E. coli $\mathrm{K} 011$ as the fermenting organisms. Both of these microorganisms were chosen because they are efficient ethanolic fermenters, with the former capable of fermenting glucose from the breakdown of cellulose, and the latter capable of fermenting both glucose and other fermentable sugars such as xylose, arabinose, and galactose from the enzymatic hydrolysis of hemicelluloses [29].

From the graph in Fig. 5, it can be seen that ethanol production started on day 1 and increased steadily in all corn stover samples, indicating that the sugars released

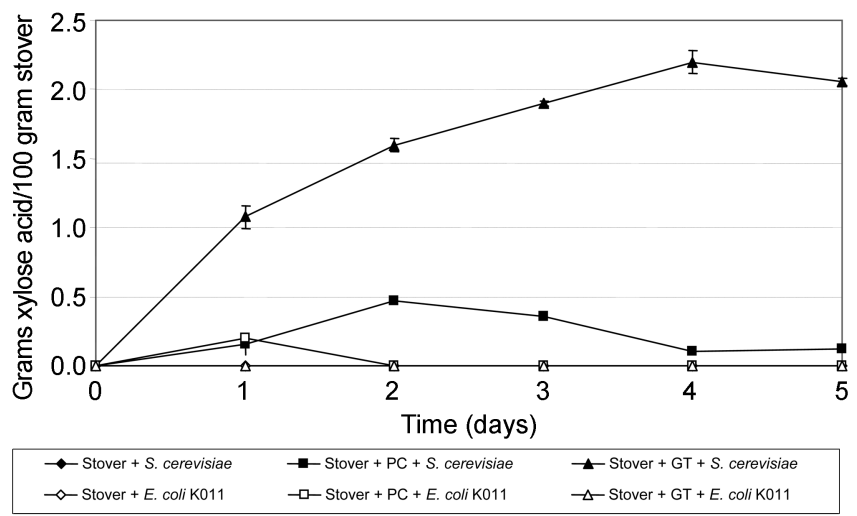

Fig. 4. Time course of xylose production.

Data points represent the average of three independent experiments $(n=3)$. PC, P. chrysosporium; GT, G. trabeum. Time zero is after 4 days of solid substrate fermentation with a specific fungus (P. chrysosporium or $G$. trabeum).

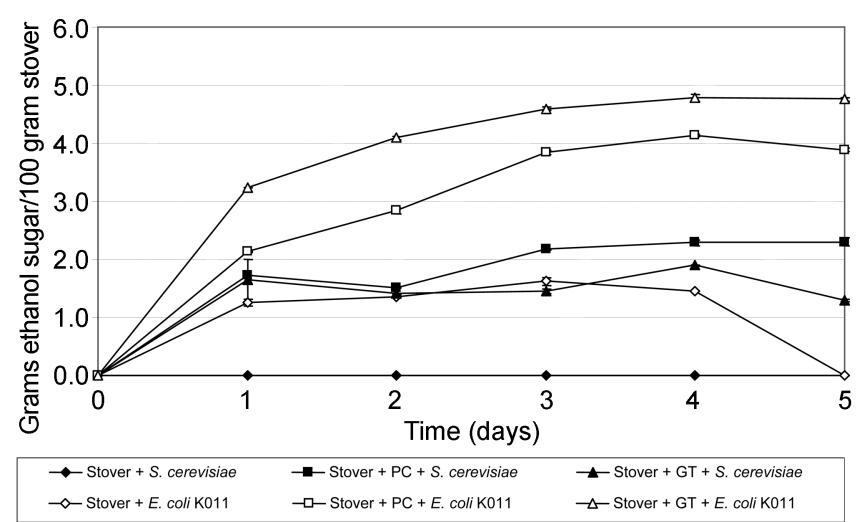

Fig. 5. Time course of ethanol production.

Data points represent the average of three independent experiments $(n=3)$. Note: PC $-P$. chrysosporium, GT - G. trabeum. Time zero is after 4 days of solid substrate fermentation with a specific fungus $(P$. chrysosporium or G. trabeum).

during saccharification were readily converted to ethanol. Ethanol production was highest on day 4 in all samples inoculated with either P. chrysosporium or G. trabeum. For stover treated with $P$. chrysosporium, the conversion to ethanol was $2.29 \mathrm{~g} / 100 \mathrm{~g}$ of stover for the sample inoculated with $S$. cerevisiae, whereas for the sample inoculated with $E$. coli $\mathrm{K} 011$, the ethanol concentration was $4.14 \mathrm{~g} / 100 \mathrm{~g}$ stover. For stover treated with G. trabeum, the conversion to ethanol was 1.90 and $4.79 \mathrm{~g} / 100 \mathrm{~g}$ stover for the samples inoculated with $S$. cerevisiae and $E$. coli K011, respectively. In general, fungi-treated samples inoculated with $E$. coli $\mathrm{K} 011 \mathrm{had}$ a greater ethanol yield. This result is due to the ability of $E$. coli $\mathrm{K} 011$ to ferment both hexoses (C6 sugars, i.e., glucose) and pentoses (C5 sugars, i.e., xylose) [29]. The results shown in Fig. 4 further support this observation; stover that was not inoculated with E. coli K011 still contained xylose even after day 5 of SSF.

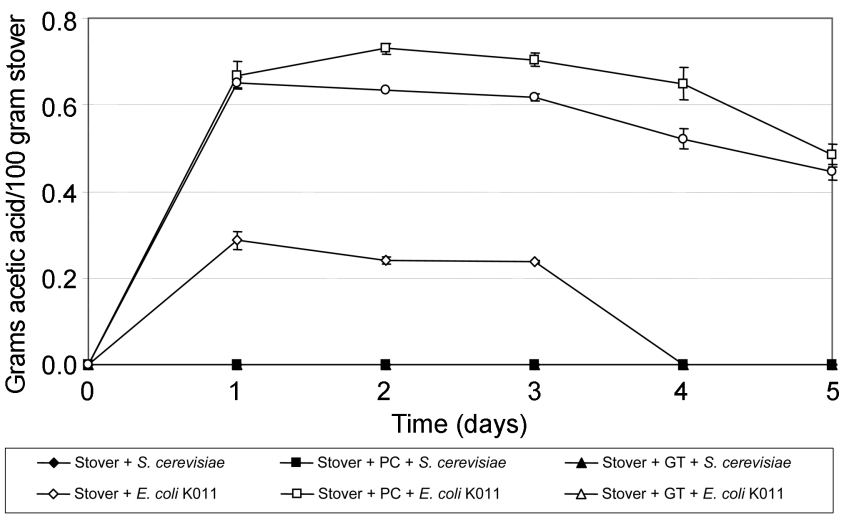

Fig. 6. Time course of acetic acid production.

Data points represent the average of three independent experiments $(n=3)$. PC, P. chrysosporium; GT, G. trabeum. Time zero is after 4 days of solid substrate fermentation with a specific fungus (P. chrysosporium or $G$. trabeum). 
Table 3. Summary of nonlinear (exponential) fit models of ethanol production $(n=3)$.

\begin{tabular}{lcc}
\hline & $\mathrm{R}^{2}$ & F-value \\
\hline Corn stover + E. coli K011 & 0.911 & 0.0265 \\
Corn stover + P. chrysosporium + S. cerevisiae & 0.925 & 0.0022 \\
Corn stover + P. chrysosporium + E. coli K011 & 0.839 & 0.0103 \\
Corn stover + G. trabeum + S. cerevisiae & 0.893 & 0.0044 \\
Corn stover + G. trabeum + E. coli K011 & 0.937 & 0.0015 \\
\hline
\end{tabular}

One interesting observation regarding the ethanol profile is the production of a trace amount of ethanol $(1.45 \mathrm{~g} /$ $100 \mathrm{~g}$ stover on day 4) in the sample inoculated only with $E$. coli $\mathrm{K} 011$. This, however, is not a new finding, as $E$. coli has been documented to secrete cellulases and several hemicellulases, such as xylanases, mannosidase, and galactases, that may have liberated xylose from hemicellulose polymers $[17,34,35]$. On day 5 , no ethanol was detected in the broth. One possible explanation is that $E$. coli consumed the minute amount of ethanol present earlier in the broth. This is a normal observation when an alternative carbon source is needed for E. coli growth [39].

Throughout the experiment, other fermentation co-products such as acetic acid and lactic acid were also recorded (Fig. 6). Acetic acid production ranged between 0.45 and $0.78 \mathrm{~g} /$ $100 \mathrm{~g}$ stover in the samples subjected to different fungal

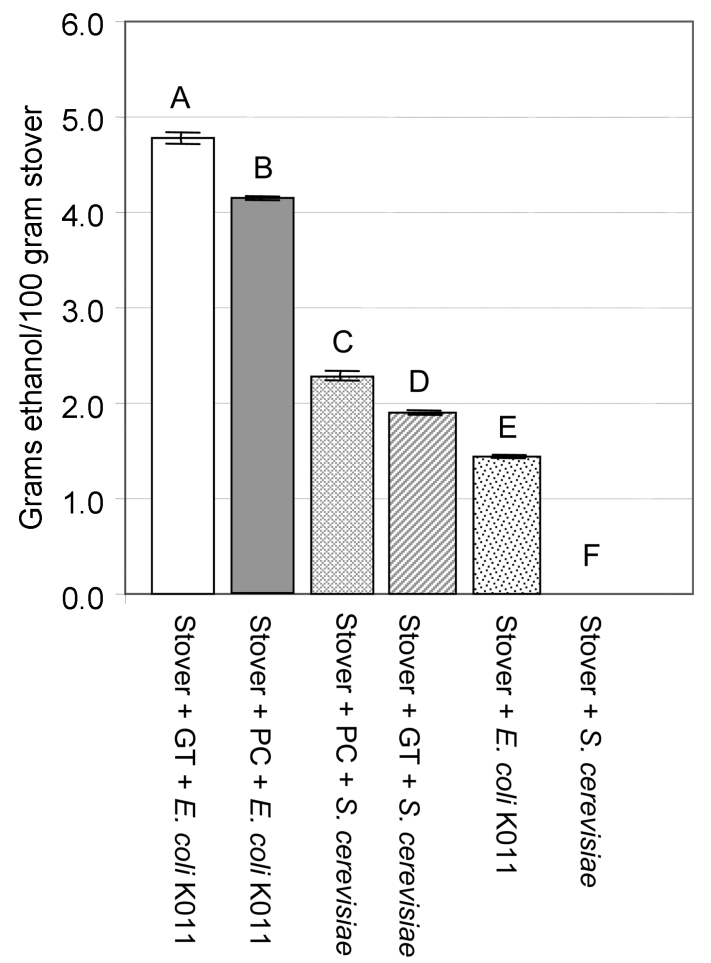

Fig. 7. Maximum ethanol production using different fungal treatments and fermentation conditions.

Letters on top of columns indicate significant differences (Student's t test, $\alpha=0.05$ ). treatments, whereas no lactic acid production was detected throughout the 5 days of SSF.

Statistical analysis via nonlinear regression using exponential model fits, as summarized in Table 3, strongly endorses the reliability of the ethanol production, with all p-values being $<0.05$. Further analysis performed using the Student's $t$ test showed statistically significant ethanol yield (Fig. 7) among the different treatments. This result reinforces the interrelationship between fungal species treatments and the fermenting organisms used.

To realize large-scale applications for cellulosic feedstocks such as corn stovers, low conversion costs are essential. The use of commercial enzymes makes the production of fuel ethanol neither economically feasible nor profitable. Furthermore, these enzymes are highly susceptible to inhibition and are very substrate specific. An ideal lignocellulolytic biocatalyst should degrade the three main components of stovers; namely, cellulose, hemicellulose, and lignin. Thus, using $P$. chrysosporium and G. trabeum to provide in situ enzymes for the degradation of the lignocellulosic components of stovers offers a promising solution. In the production of fuel ethanol from corn stovers, the optimization of this process can lead to reduced costs, as ethanol plants can produce their own enzymes to supplement the use of commercial enzymes. Another advantage in using this process is that it is an environmentally friendlier approach that eliminates the need to perform potentially detrimental pretreatments.

\section{Acknowledgments}

This work was financially supported by Universiti Malaysia Sarawak (UNIMAS) and the Malaysian Ministry of Higher Education. We thank Patrick Murphy and Dr. Kenneth Moore (Department of Agronomy, Iowa State University, Ames, IA, USA) for help with the corn stover compositional analysis and Carol Ziel and Dr. John Strohl for technical assistance.

\section{REFERENCES}

1. Abbas, A., H. Koc, F. Liu, and M. Tien. 2005. Fungal degradation of wood: Initial proteomic analysis of extracellular proteins of 
Phanerochaete chrysosporium grown on oak substrate. Curr. Genet. 47: 49-56.

2. Adney, B. and J. Baker. 2008. Measurement of Cellulase Activities. Laboratory Analytical Procedure (LAP). Technical Report NREL/TP-510-42628. Available at http://www.nrel.gov/ biomass/pdfs/42628.pdf.

3. Antai, S. P. and D. L. Crawford. 1981. Degradation of softwood, hardwood, and grass lignocelluloses by two Streptomyces strains. Appl. Environ. Microbiol. 42: 378-380.

4. Arantes, V. and A. M. F. Milagres. 2006. Degradation of cellulosic and hemicellulosic substrates using a chelator-mediated Fenton reaction. J. Chem. Technol. Biotechnol. 81: 413-419.

5. Brekke, K. 2005. The promise of cellulosic ethanol. Ethanol Today 6: 32-35.

6. Cantarella, M., L. Cantarella, A. Gallifuoco, A. Spera, and F. Alfani. 2004. Effect of inhibitors released during steam-explosion treatment of poplar wood on subsequent enzymatic hydrolysis and SSF. Biotechnol. Progress 20: 200-206.

7. Chundawat, S. P. S., B. Venkatesh, and B. E. Dale. 2007. Effect of particle size based separation of milled corn stover on AFEX pretreatment and enzymatic digestibility. Biotechnol. Bioeng. 96: $219-231$.

8. Cohen, R., M. R. Suzuki, and K. E. Hammel. 2005. Processive endoglucanase active in crystalline cellulose hydrolysis by the brown rot basidiomycete Gloeophyllum trabeum. Appl. Environ. Microbiol. 71: 2412-2417.

9. Crawford, D. L. and A. L. Pometto III. 1988. Acid-precipitable polymeric lignin: Production and analysis. Methods Enzymol. 161: 35-47.

10. Daniel, G., J. Volc, L. Filonova, O. Plíhal, E. Kubátov, and P. Halada. 2007. Characteristics of alcohol oxidase from the fungus Gloeophyllum trabeum, an extracellular source of $\mathrm{H}_{2} \mathrm{O}_{2}$ in brown rot decay of wood. Appl. Environ. Microbiol. 73: 6241-6253.

11. de La Torre Ugarte, D. G., M. E. Walsh, H. Shapouri, and S. P. Slinsky. 2003. The Economic Impacts of Bioenergy Crop Production on U.S. Agriculture. Agricultural Economic Report No. 816. U. S. Department of Agriculture, Economic Research Service, U. S. Government Printing Office, Washington, DC.

12. Donohoe, B. S., M. J. Selig, S. Viamajala, T. B. Vinzant, W. S. Adney, and M. E. Himmel. 2009. Detecting cellulase penetration into corn stover cell walls by immuno-electron microscopy. Biotechnol. Bioeng. 103: 480-489.

13. Duguid, K. B., M. D. Montross, C. W. Radtke, C. L. Crofcheck, L. M. Wendt, and S.A. Shearer. 2009. Effect of anatomical fractionation on the enzymatic hydrolysis of acid and alkaline pretreated corn stover. Bioresour. Technol. 100: 5189-5195.

14. Eliasson, A., C. Christensson, C. F. Wahlbom, and B. H. Gerdal. 2000. Anaerobic xylose fermentation by recombinant Saccharomyces cerevisiae carrying XYL1, XYL2, and XKS1 in mineral medium chemostat cultures. Appl. Environ. Microbiol. 66: 3381-3386.

15. Galbe, M. and G. Zacchi. 2007. Pretreatment of lignocellulosic materials for efficient bioethanol production. Adv. Biochem. Eng. Biotechnol. 108: 41-65.

16. García-Cubero, M. T., G. González-Benito, I. Indacoechea, M. Coca, and S. Bolado. 2009. Effect of ozonolysis pretreatment on enzymatic digestibility of wheat and rye straw. Bioresour. Technol. 100: 1608-1613.
17. Gebler, J. C., R. Aebersold, and S. G. Withers. 1992. Glu-537, not Glu-461, is the nucleophile in the active site of (lac Z) $\beta$ galactosidase from Escherichia coli. J. Biol. Chem. 267: 1112611130.

18. Ghose, T. K. 1987. Measurement of cellulase activites. Pure Appl. Chem. 59: 257-268.

19. He, X., Y. Miao, X. Jiang, Z. Xu, and P. Ouyang. 2010. Enhancing the enzymatic hydrolysis of corn stover by an integrated wet-milling and alkali pretreatment. Appl. Biochem. Biotechnol. 160: 2449-2457.

20. Hendriks, A. T. W. M. and G. Zeeman. 2009. Pretreatments to enhance the digestibility of lignocellulosic biomass. Bioresour. Technol. 100: 10-18.

21. Keating, J. D., C. Panganiban, and S. D. Mansfield. 2006. Tolerance and adaptation of ethanologenic yeasts to lignocellulosic inhibitory compounds. Biotechnol. Bioeng. 93: 1196-1206.

22. Kerem Z., K. A. Jensen Jr, and K. E. Hammel. 1999. Biodegradative mechanism of the brown rot basidiomycete Gloeophyllum trabeum: Evidence for an extracellular hydroquinone-driven Fenton reaction. FEBS Lett. 446: 49-54.

23. Kersten, P. and D. Cullen. 2007. Extracellular oxidative systems of the lignin-degrading basidiomycete Phanerochaete chrysosporium. Fungal Gen. Biol. 44: 77-87.

24. Keshwani, D. R. and J. J. Cheng. 2009. Switchgrass for bioethanol and other value-added applications: A review. Bioresour. Technol. 100: $1515-1523$.

25. Kim, T. H., N. P. Nghiem, and K. B. Hicks. 2009. Pretreatment and fractionation of corn stover by soaking in ethanol and aqueous ammonia. Appl. Biochem. Biotechnol. 153: 171-179.

26. Kumar, R. and C. E. Wyman. 2009. Cellulase adsorption and relationship to features of corn stover solids produced by leading pretreatments. Biotechnol. Bioeng. 103: 252-267.

27. Lim, K. N. 2004. Conversion of lignocellulosic biomass to fuel ethanol - A brief review. The Planter 80: 517-524.

28. Liu, S., K. A. Skinner-Nemec, and T. D. Leathers. 2008. Lactobacillus buchneri strain NRRL B-30929 converts a concentrated mixture of xylose and glucose into ethanol and other products. J. Ind. Microbiol. Biotechnol. 35: 75-81.

29. Liu, H., M. Yan, C. Lai, L. Xu, and P. Ouyang. 2010. gTME for improved xylose fermentation of Saccharomyces cerevisiae. Appl. Biochem. Biotechnol. 160: 574-582.

30. Martinez, D., L. F. Larrondo, N. Putnam, M. D. SollewijnGelpke, K. Huang, J. Chapman, et al. 2004. Genome sequence of the lignocellulose degrading fungus Phanerochaete chrysosporium strain RP78. Nature Biotechnol. 22: 695-700.

31. Mussatto, S. I., M. Fernandes, A. M. F. Milagres, and I. C. Roberto. 2008. Effect of hemicellulose and lignin on enzymatic hydrolysis of cellulose from brewer's spent grain. Enzyme Microb. Technol. 43: 124-129.

32. Nigam, J. N. 2001. Ethanol production from wheat straw hemicellulose hydrolysate by Pichia stipitis. J. Biotechnol. 87: $17-27$.

33. Nguyen, M. T., S. P. Choi, J. Lee, J. H. Lee, and S. J. Sim. 2009. Hydrothermal acid pretreatment of Chlamydomonas reinhardtii biomass for ethanol production. J. Microbiol. Biotechnol. 19: 161-166.

34. Okuyama, M., A. Kaneko, H. Mori, S. Chiba, and A. Kimura. 2005. Structural elements to convert Escherichia coli alpha- 
xylosidase (Yicl) into alpha-glucosidase. FEBS Lett. 580: 27072711.

35. Park, Y. W. and H. D. Yun. 1999. Cloning of the Escherichia coli endo-1,4-D-glucanase gene and identification of its product. Mol. Gen. Genet. 261: 236-241.

36. Pordesimo, L. O., B. R. Hames, S. Sokhansanj, and W. C. Edens. 2005. Variation in corn stover composition and energy content with crop maturity. Biomass Bioenergy 28: 366-374.

37. Ramos, L. P. 2003. The chemistry involved in the steam pretreatment of lignocellulosic materials. Quim. Nova 26: 863871.

38. Rasmussen, M. L., P. Shrestha, S. K. Khanal, A. L. Pometto III, and J. (Hans) van Leeuwen. 2010. Sequential saccharification of corn fiber and ethanol production by the brown rot fungus Gloeophyllum trabeum. Bioresour. Technol. 101: 3526-3533.

39. Salaspuro, V., S. Nyfors, R. Heine, A. Siitonen, M. Salaspuro, and H. Jousimies-Somer. 1999. Ethanol oxidation and acetaldehyde production in vitro by human intestinal strains of Escherichia coli under aerobic, microaerobic, and anaerobic conditions. Scand. J. Gastroenterol. 34: 967-973.

40. Sanchez, C. 2009. Lignocellulosic residues: Biodegradation and bioconversion by fungi. Biotechnol. Adv. 27: 185-194.

41. Saqib, A. A. N. and P. J. Whitney. 2006. Role of fragmentation activity in cellulose hydrolysis. Int. Biodeterior. Biodegrad. 58: $180-185$.

42. Selig, M. J., T. B. Vinzant, M. E. Himmel, and S. R. Decker. 2009. The effect of lignin removal by alkaline peroxide pretreatment on the susceptibility of corn stover to purified cellulolytic and xylanolytic enzymes. Appl. Biochem. Biotechnol. 155: 397-406.

43. Shrestha, P., M. Rasmussen, S. K. Khanal, A. L. Pometto III, and J. (Hans) van Leeuwen. 2008. Solid-substrate fermentation of corn fiber by Phanerochaete chrysosporium and subsequent fermentation of hydrolysate into ethanol. J. Agric. Food Chem. 56: $3918-3924$.

44. Shrestha, P., S. K. Khanal, A. L. Pometto III, and J. (Hans) van Leeuwen. 2009. Enzyme production by wood-rot and soft-rot fungi cultivated on corn fiber followed by hydrolysate fermentation to ethanol. J. Agric. Food Chem. 57: 4156-4161.

45. Shrestha, P., S. K. Khanal, A. L. Pometto, and J. (Hans) van Leeuwen. 2010. Ethanol production via in situ fungal saccharification and fermentation of mild alkali and steam pretreated corn fiber. Bioresour. Technol. 101: 8698-8705.
46. Sokhansanj, S., A. Turhollow, J. Cushman, and J. Cundi. 2002. Engineering aspects of collecting corn stover for bioenergy. Biomass Bioenergy 23: 347-355.

47. Sørensen, A., P. J. Teller, T. Hilstrøm, and B. K. Ahring. Hydrolysis of Miscanthus for bioethanol production using dilute acid presoaking combined with wet explosion pre-treatment and enzymatic treatment. Bioresour. Technol. 99: 6602-6607.

48. Su, D., J. Sun, P. Liu, and Y. Lu. 2006. Effects of different pretreatment modes on the enzymatic digestibility of corn leaf and corn stalk. Chin. J. Chem. Eng. 14: 796-801.

49. Sun, Y. and J. Cheng. 2002. Hydrolysis of lignocellulosic materials for ethanol production: A review. Bioresour. Technol. 83: 1-11.

50. Suzuki, H., K. Igarashi, and M. Samejima. 2008. Real-time quantitative analysis of carbon catabolite derepression of cellulolytic genes expressed in the basidiomycete Phanerochaete chrysosporium. Appl. Microbiol. Biotechnol. 80: 99-106.

51. Varga, E., H. B. Klinke, K. Rczey, and A. B. Thomsen. 2004. High solid simultaneous saccharification and fermentation of wet oxidized corn stover to ethanol. Biotechnol. Bioeng. 88: 567-574.

52. Vogel, K. P., J. F. Pedersen, S. D. Masterson, and J. J. Toy. 1999. Evaluation of a filter bag system for NDF, ADF and IVDMD forage analysis. Crop Sci. 39: 276-279.

53. Weiss, N. D., J. D. Farmer, and D. J. Schell. 2010. Impact of corn stover composition on hemicellulose conversion during dilute acid pretreatment and enzymatic cellulose digestibility of the pretreated solids. Bioresour. Technol. 101: 674-678.

54. Wymelenberg, A. V., G. Sabat, B. Martinez, A. S. Rajangam, T. T. Teeri, J. Gaskell, P. J. Kersten, and D. Cullen. 2005. The Phanerochaete chrysosporium secretome: Database predictions and initial mass spectrometry peptide identifications in cellulosegrown medium. J. Biotechnol. 118: 17-34.

55. Yang, B., D. M. Willies, and C. E. Wyman. 2006. Changes in the enzymatic hydrolysis rate of Avicel cellulose with conversion. Biotechnol. Bioeng. 94: 1122-1128.

56. Yang, C. P., Z. Q. Shen, G. Yu, and J. L. Wang. 2008. Effect and after effect of radiation pretreatment on enzymatic hydrolysis of wheat straw. Bioresour. Technol. 99: 6240-6245.

57. Yu, J., J. Zhang, J. He, Z. Liu, and Z. Yu. 2009. Combinations of mild physical or chemical pretreatment with biological pretreatment for enzymatic hydrolysis of rice hull. Bioresour. Technol. 100: 903-908. 